\title{
LIMA BARRETO \\ um olhar deslocando-se
}

Elvya Ribeiro Dereira

Ah! A literatura ou me mata ou me dá o que eu peço dela. Lima Barreto, Diário do hospício.

Com o olhar crítico na tradição, e descentrado em relação aos modismos de seu tempo, o escritor Lima Barreto situa-se como intelectual dissidente, tanto em relação ao abstrato ufanismo nacionalista de conotação romântica, quanto aos referenciais alinhados com a produção cultural da belle époque.

Ao retomar, por exemplo, os textos escritos sobre o Brasil que se encontram arquivados na biblioteca de Policarpo Quaresma, Lima Barreto o faz para reinseri-los numa abordagem reflexiva de sabor satírico-parodística, que desloca, seja via ironia crítica ou riso desestruturador, os ufanismos, (os eurocêntricos ou os xenófobos) e repõe a discussão da identidade nacional num contexto onde não se pode mais desconhecer o aspecto plural de nossa cultura.

No contraponto com a visão alencariana, acerca do papel exercido pelo índio na cena de fundação da nossa cultura, para apontarmos um exemplo, o indianismo revisitado de Quaresma desvia-se do eixo da discussão que perfaz o caminho da integração das raças, para se fixar, na absorção dos valores socioculturais do índio sua língua, seus costumes, na tentativa de desrecalcá-los.

Ao aproximarmos o indianismo de Quaresma ao de Alencar, que é uma fonte de sua motivação nacionalista (já que figura todo, juntamente com Durão e Gonçalves Dias, na sua brasiliana), temos um cruzamento de discursos que, se alimentando am- 
bos de uma retórica idealista, atingem porém planos socioculturais e políticos bastante diferenciados. Alencar ressalta a figura mítica e ancestral do índio, idealizada a partir de modelos europeus (filosóficos e literários) de pureza, honra e bravura, para inscrevê-la no corpo literário ( no nível do imaginário), da nação. Já em Triste fim Policarpo Quaresma, Lima Barreto presentifica a questão indianista, alojando-a no seio de uma recente e conturbada sociedade republicana e, com isso, desloca o indianismo do plano do imaginário, de extração literária e nacionalista, para o campo dos embates sociais e políticos do seu tempo. A retórica mítico-ufanista, com o personagem, Major Quaresma, atualiza-se num plano da realidade imediata, concreta, num visionário projeto de feição reformista, mas socialmente engajado, com claras implicações políticas. Nesse "quixotesco" deslocamento de planos temporais (passado/presente) e formais (em que literatura e realidade, mundo imaginário e ações pragmáticas se permutam ou se confundem) não é mais possível a presença física do índio (dizimado ou excluído pelo processo colonizador) em encenações (a)históricas; não há mais a presença de um herói ou de uma raça autóctone; o que se evoca então na matriz indianista de Quaresma são apenas valores lingüísticos e sociais de um índio distante e marginalizado, em contraposição aos valores já estabilizados do colonizador. De imediato, a atitude excêntrica do Major Quaresma vem à tona, num jogo paródico com o indianismo romântico cujo efeito cômico matiza, mas não apaga, a dimensão crítica do romance.

No romance, como no Romantismo, entretanto, uma situação comum pode ser detectada: o apagamento, a ausência do índio propriamente dito no contexto em que as obras são produzidas. O índio estaria na "origem", teria uma cultura, mas já não tem presença humana concreta, já não contracena com os pares da sociedade oitocentista. Do índio alencariano restou sobretudo um passado mítico, uma figuração idealizada e a-histórica; já em Triste fim, subsiste fragmentariamente o espectro de seus valores culturais, ironicamente pontuados na contramão da história do colonizador.

Do enquadramento nacionalista de Policarpo Quaresma (via brasiliana) ficam de fora o negro e sua cultura. Isto é curioso porque, no contexto em que a narrativa se passa, como já vimos, distante é a figura do índio (como era também para os românticos) enquanto que o negro é uma presença bastante visível. Além do que, a abolição foi uma das bandeiras do movimento republicano e nada seria mais plausível do que a incorporação do negro no projeto nacionalista de Policarpo Quaresma, que era um defensor do poder constituído, (defesa que se mantém em função daquilo que ele 
considera como altamente patriótico $)^{1}$. Num certo sentido, a elisão do negro do projeto de Quaresma ecoa as dificuldades que então rondavam o exercício intelectual no que concerne à representação da cultura negra. Como dar visibilidade a uma presença que incomoda? Seria possível se desconsiderar as teses étnico-pessimistas ou racistas em voga? Como incorporá-la (a cultura negra) a um projeto republicano que traz em sua face todo um verniz modernizador, que, na esteira disciplinadora do positivismo e do cientificismo evolucionista, previa o branqueamento futuro do povo brasileiro?

No projeto de maquiagem do Rio de Janeiro (que na época se apresentava como "metonímia" de Brasil), para fazer frente aos ideais da civilização européia, a sociedade republicana não contava com o elemento negro. Como bem observa José Murilo de Carvalho:

O Rio tornou-se um centro culturalmente cosmopolita, um centro importador e consumidor voraz dos produtos da cultura européia, por mais variados e desbaratados que fossem esses produtos. Várias correntes políticas e estéticas encontravam aqui seguidores. Mas tudo se construía no vazio em função de imitar a Europa. (...) A diversidade social do país e, particularmente, da cidade, era incompatível com o modelo oficial. De fato, como seria possível recuperar a realidade do Rio, sua cultura popular, sua riquíssima cultura popular, se esta cultura tinha muito a ver com a população ex-escrava, com a população negra, com a população marginal? Esta cultura não cabia nos moldes da imagem europeizada do país. Daí as contradições e os bloqueios que se interpunham no caminho da criatividade dos intelectuais (Carvalho, 1988: 19).

No romance de Lima Barreto, paralelo ao silêncio do Major Quaresma em relação ao negro, estão algumas situações do enredo e algumas observações do narrador que formam certos estereótipos quase sempre étnico-pessimistas, comuns à tradição literária e às teorias raciais em voga. Em outros termos, poderíamos dizer que o elemento negro não se inclui no horizonte das reformas radicais do Major Quaresma, sobretudo por uma razão de ordem intrínseca ao enredo, como atesta a sua própria brasiliana composta por autores para os quais a presença do negro representou uma dificuldade estética e um incômodo ideológico. Assim, para esses autores, como para

1 É bom lembrarmos que Quaresma “imaginava [para o Brasil] um governo forte, respeitado e inteligente... espalhando sábias leis agrárias, levantando o cultivador... Um governo forte, até à tirania" (Barreto, 1969: 184-5). Tal "tirania" adquire certa plausibilidade, quando se tem em vista que Quaresma adotava uma forma "ideal de patriotismo", qual seja, aquela que acima dos interesses políticos e individuais viesse a "contribuir para ...felicidade e prosperidade" da pátria (idem, p. 282). 
Quaresma, restava a alternativa de não representá-lo, ou fazê-lo estereótipo. Se a atitude do personagem com relação ao negro apoia-se na estrutura interna do romance, a do narrador deixa transparecer ainda a dificuldade que rondava os intelectuais da época, num contexto em que se forjava uma modernizacão de superfície da nossa sociedade, aquilatada, entre outros produtos de importação, pelas teorias científicas de cunho predominantemente étnico-pessimistas.

Lima Barreto nasceu a 13 de maio de 1881, sete anos antes da Abolição da Escravatura. Sobre a coincidência das datas confessa o autor na crônica "Maio":

Estamos em maio, o mês das flores, o mês sagrado pela poesia. Não é sem emoção que o vejo entrar. Nasci sob o seu signo, a treze, e creio que em sexta-feira; e por isso, também à emoção que o mês sagrado me traz, misturam-se recordações da minha meninice.

Agora mesmo estou a lembrar-me que, em 1888, dias antes da data áurea, meu pai chegou em casa e disse-me: a lei da abolição vai passar no dia dos teus anos. E de fato passou; e nós fomos esperar a assinatura no Largo do Paço.

Eu tinha sete anos e o cativeiro não me impressionava. Não lhe imaginava o horror; não conhecia a sua injustiça. Eu me recordo, nunca conheci uma pessoa escrava. Criado no Rio de Janeiro, na cidade, onde já os escravos rareavam, faltava-me o conhecimento direito da vexatória instituição, para lhe sentir bem os aspectos hediondos (Barreto, 1993: $313-5)^{2}$.

Indiscutivelmente, o escritor deixa transparecer em seus depoimentos e em suas obras ficcionais o peso do estigma racial em voga na época. "É triste não ser branco", escreveu, no seu Diário íntimo, Lima Barreto, resumindo numa confidência amarga, como diz Francisco de Assis Barbosa, "todas as limitações que sofria. Mais do que um complexo, a cor era uma barreira para sua vocação de escritor. Tinha que transpô-la. Mesmo que não conseguisse vencer o complexo" (Barbosa, 1988: 122).

Voltando a Triste fim de Policarpo Quaresma, vemos que esta questão étnica se apresenta com seus impasses característicos de um discurso que, mesmo crítico, sofre limitações teóricas. Podemos citar como exemplo as descrições, pelo narrador, das

\footnotetext{
${ }^{2}$ Sem pretender estabelecer relações de causa e efeito (numa visão determinista) entre vida e obra, podemos recorrer a alguns depoimentos de Lima Barreto no intuito de buscarmos mais elementos que pontuem tal contexto. Neste se confundem, quando da representação do negro: vozes que divulgam teorias científicas deterministas; que ratificam estereótipos racistas; formas de resistência aos preconceitos raciais e sociais; a importância da luta pelo reconhecimento dos que estão à margem de um processo modernizador; a desesperança; a melancolia.
} 
seguintes personagens: Olga, que tem alguns traços positivos tributados "às proximidades européia do seu nascimento, que a fizeram um pouco diferente das nossas moças" (Barreto, 1969: 58); Felizardo, "camarada magro, alto, de longos braços, longas pernas, como símio" (p. 153); e Mané Candeeiro, que "era claro e tinha umas feições regulares, cesarianas, duras e fortes, um tanto amolecidas pelo sangue africano" (p. 174).

Além dessas passagens, acrescentamos outras muito ilustrativas dessa visão contraditória do narrador no que diz respeito, ainda, ao aspecto "desolador" da população que habita o interior do país. Vejamos o modo como descreve os filhos de Felizardo, que se assemelhava a um símio, e da Sinhá Chica, que vivia mergulhada nos misteriosos poderes do feitiço:

Eram dous rapazes ambos inertes, moles, sem força e sem crenças, nem mesmo a da feitiçaria, das rezas e benzeduras, que fazia o encanto da mãe e merecia o respeito do pai./ Não houve quem os fizesse aprender qualquer coisa e os sujeitasse a um trabalho contínuo. De quando em quando (...) faziam uma talha de lenha e vendiam ao primeiro taverneiro pela metade do valor; voltavam para casa alegres, satisfeitos com um lenço de cores vivas, um vidro de água-de-colônia, um espelho, bugigangas que denunciavam ainda neles gostos bastante selvagens (p. 265-6; grifos nossos).

Logo depois, o narrador submete a este crivo pessimista um universo bem maior: essa "atonia da nossa população, essa espécie de desânimo doentio, de indiferença por tudo e todas as coisas, cercam de uma caligem de tristeza desesperadora a nossa raça e tira-lhe o encanto, a poesia e o viço sedutor de plena natureza (p. 267). Esta representação desoladora do homem do campo, no início do século, é salientada por Antonio Candido, ao discorrer sobre a "instabilidade" da palavra nacionalismo neste século. O crítico destaca a importância de algumas pesquisas e descobertas científicas que revelam $o$ estado calamitoso das populações rurais, que viriam contrariar uma visão tranqüilamente otimista da nação. Tal quadro tem uma referência nas pesquisas de Carlos Chagas "sobre o estado catastrófico da saúde na maioria do interior, corroído por doenças como a que tomou o nome do seu descobridor [doença de Chagas] em 1909”. Segundo ainda o crítico, "este quadro sombrio desencadeou a reação indignada dos partidários da visão eufórica (...). Com isto estocou-se firmemente o regionalismo idílico, ou pelo menos pitoresco, da maioria dos escritores do gênero" (Candido, 1995: 295-6).

Para além dessa complexa representação do negro e do mestiço, o narrador e o romance barretiano perpassam espaços sociais marginalizados (político, social e economicamente), reafirmando muitas das preocupações que moveram esse incansável cronista do cotidiano, Lima Barreto. 
No Rio de Janeiro do início do século XX, as desigualdades sociais acentuam-se diante da face "modernizadora" com a qual se reveste o regime republicano recém implantado, que se mostra ineficaz quando se trata dos anseios e necessidades daqueles que já estão à margem de um projeto modernizador excludente e de fachada: "Não será, pensei de mim para mim, que a República é o regímen da fachada, da ostentação, do falso brilho e luxo de parvenu, tendo como repoussoir a miséria geral" (Barreto, "15 de novembro", Marginália, 1961: 35).

$\mathrm{Na}$ esteira desse processo modernizador capitaneado pelos republicanos se inscrevem as reformas urbanas, implementadas a partir da primeira década do século XX. Assim, no grande palco que era a então capital da República, se dá o bota-abaixo da cidade, como gostava de referir Lima Barreto, pelo então prefeito do Rio de janeiro, Pereira Passos. Entre outras críticas, o escritor denuncia a repartição do Rio de Janeiro em duas cidades: a que vai do Centro (reformado) a Botafogo, espaços de um Rio civilizado, ou em vias de civilização, endereços de uma elite carioca; e a que ocupa uma parte da zona suburbana, mais precisamente, as encostas dos morros, as margens das linhas de trem, as beiras dos mangues.

São espaços quase indistintos em sua pobreza, povoados pelas suas indigentes "famílias de olhos", para lembramos uma contundente imagem de Baudelaire, ao abordar os efeitos da grande reforma urbana parisiense do século passado ${ }^{3}$. É importante salientar que essa divisão da cidade em espaços sociais visivelmente distintos não demanda de uma lógica maniqueísta, já que nos subúrbios cartografados por Lima Barreto vão estar plantados, também, sítios, chácaras, construções ("de gosto duvidoso, mixórdia de estilos, incompatíveis com a nossa feição tropical”), ocupadas por uma elite emergente, ávida por imitar Botafogo, que, por sua vez, imita a Europa. Entre os vários desenhos caricaturais desse duvidoso gosto suburbano, destacamos:

O chalé, porém é expressão arquitetônica do subúrbio. Alguns proprietários, poupando a platibanda e os lambrequis, não esquecem de dar ao telhado do edifício o jeito característico e de arrematar as duas extremidades da cumeeira com as flechas denunciativas. Em dias de névoa, em dias frios, se olharmos um trecho do alto, é como se estivéssemos na Suiça ou na Holanda (Vida e Morte de M. J. Goñaga de Sá, s/d, p. 103).

\footnotetext{
${ }^{3}$ Charles Baudelaire, "Os olhos dos pobres", in Petits poèmes en prose; pequenos poemas em prosa; trad. de
} Dorothée de Bruchard. Florianópolis: Ed. da UFSC / Aliança Francesa, 1988. 
O mapeamento da cidade partida apoia-se num contundente discurso que tenta denunciar tanto a vacuidade das reformas urbanísticas para a população que já habitava os subúrbios, como seu decurso asséptico, leia-se excludente, a promover, compulsoriamente, a debandada de outros tantos do Centro para além-Botafogo. Não podemos, contudo, deixar de anotar algumas passagens nas quais, Lima Barreto, esboçando um meio sorriso, ironiza a vaidade dos que moram ou desejam morar em Botafogo (quiçá, ele mesmo):

Foi em um domingo. Tomei um bonde da Jardim, aí, na avenida para visitar um amigo / Como todo sujeito que é rico ou se supõe ou quer passar como tal, o meu amigo morava para as bandas de Botafogo.

Ia satisfeito. Pois há muito não me perdia por aquelas bandas da cidade e me aborrecia com a monotonia dos meus dias, vendo as mesmas paisagens e olhando sempre as mesmas fisionomias. Fugiria, assim, por algumas horas, à fadiga visual de contemplar as montanhas desnudas que marginam à Central, da estação inicial até Cascadura. Morava eu nos subúrbios. Fui visitar portanto, o meu amigo, naquela Botafogo catita, Meca das ambições dos nortistas, dos sulistas e dos cariocas (Barreto, 1979: 38-9).

Como alerta Francisco Assis Barbosa, "pode parecer para alguns que Lima Barreto cultivava um certo saudosismo em relação ao Rio da sua infância e da sua mocidade. Apesar das suas idéias anarquistas, e da posição assumida em defesa das greves operárias, nessa mesma quadra, não deixa de fazer um paralelo da cidade do Império e na República”. Em certa medida, não se pode desconsiderar esse dado. Contudo, o que prevalece nessa sua postura, para além de um "saudosismo", é o compromisso de denunciar "os homens ricos e famosos, os agentes imobiliários os pseudo-urbanistas [especuladores], que não estavam preocupados com a natureza" (Barbosa, 1987: 29), nem tampouco com a grande parcela da sociedade a ser arrancada dos morros, do centro do Rio, para locais distantes da visão já meramente "binocular" dos políticos e intelectuais adeptos do lema "o Rio civiliza-se", lema que, por sua vez, ecoava aquele outro - "Ordem e progresso", e vice-versa. O Rio civilizase. Este é o arremate com o qual Lima Barreto fecha o texto "A volta" (1915). Nele, podemos acompanhar outros dados dramáticos dessa questão. A transformação da cidade do Rio de Janeiro num "Eldorado", serviu também de isca, afirma o escritor, para atrair (num movimento, aparentemente, inverso ao que se impôs à população pobre que habitava o centro do Rio) pessoas e famílias que se quisessem instalar em núcleos coloniais do Rio de Janeiro. 
A estas pessoas o governo resolveu fornecer passagens, terras, instrumentos aratórios, auxílios por alguns meses. (...) Porque o Senhor Rio Branco, o primeiro brasileiro como aí dizem, cismou que havia de fazer do Brasil grande potência, que devia torná-lo conhecido na Europa, que (...) devia dotar a sua capital de avenidas, de boulevards, elegâncias bem idiotamente binoculares e toca a gastar dinheiro (...) e a pobre gente que mourejava lá fora, entre a febre palustre e a seca implacável, pensou que aqui fosse o Eldorado e lá deixou as suas choupanas, o seu sapé, o seu aipim, o seu porco, correndo ao Rio de Janeiro a apanhar algumas moedas da cornucópia inesgotável.

Ninguém os viu lá, ninguém quis melhorar a sua sorte no lugar que o sangue dos seus avós regou o eito. Fascinaram-no para a cidade e eles agora voltam, voltam pela mão da polícia como reles vagabundo. (...) o Rio de Janeiro, capital de um país que recebeu durante quase três séculos milhões de pretos, não deve ter pretos.

E com semelhantes raciocínios foram pertubar a vida da pobre gente que vivia a sua medíocre vida aí por fora, para satisfazer obsoletas concepções sociais, (...) transformando-lhes os horizontes e dando-lhes inexequíveis esperanças.

Voltam agora (...) donde nunca deviam ter vindo para atender tolas vaidades de taumaturgos políticos e encher de misérias uma cidade cercada de terras abandonadas que nenhum dos nossos consumados estadistas soube ainda torná-las produtivas e úteis. O Rio civiliza-se! (Barreto, Vida urbana, in 1961: 82-3)

A intolerância dos nossos republicanos para com outros "locais da cultura", que estavam fora das margens delimitadas pelo esquadro da "ordem e progresso", é recorrentemente pontuada na produção de Lima Barreto. Na crônica "Feiras e mafuás", por exemplo, ele rememora algumas manifestações de uma cultura popular proscrita pelo novo código cientificista de posturas adotado pelos estadistas de plantão:

Ainda é do tempo da minha meninice, as barraquinhas que se armavam no Campo de Sant'Ana, no largo em frente ao Quartel General, aí pelo mês de junho, por ocasião das festas tradicionais deste mês. Eram as barraquinhas de Santo Antônio ou de Sant'Ana, não me lembro ao certo o nome popular que tinham; mas sei bem que os poderes públicos do tempo toleravam essa espécie de feira. (...) Veio a República, e logo as novas autoridades acabaram com aquela folgança de mês; a República chegou austera e ríspida. Ela vinha armada com a Política Positiva de Comte, e com os seus complementos: um sabre e uma carabina (Barreto, Feiras e mafuás, 1961: 21-2).

De dentro do ato de rememorar - uma afirmação de um sentimento de exclusão individual e coletivo, assoma o desejo de reconhecimento negado pela nova ordem. As barraquinhas estavam geograficamente postas no "local" (Campo de Sant'Anna) onde se deu a proclamação da república, mas culturalmente muito distantes de seu novo código de posturas, nele não estavam previstas relações de fronteiras, negociá- 
veis, entre o quartel e as barraquinhas. Não custar lembrar, ainda, que foram esses mesmos complementos republicanos, o sabre e a carabina, que, funcionando aqui, ali ou acolá, por esses Brasis em fora, conforme registra Lima Barreto, na mesma crônica (p. 22), levaram a politica positivista até Canudos, patrocinando um dos maiores genocídios da história brasileira.

Lima Barreto, à sua maneira, ou à maneira de Policarpo, ou de Gonzaga de Sá, nutria um ciúme de nativo pela sua cidade, o Rio de Janeiro. Contudo, a tal "nativismo", se sobrepõem um enfoque crítico e uma voz inconformada atinentes às distorções urbanísticas do que se chamavam na época melhoramentos do Rio de Janeiro, ao que, direta ou indiretamente (além da derrubada de árvores, da destruição das florestas circundantes, do aterro da baía de Guanabara, do arrasamento de morros), estava aliado um apagamento progressivo da memória cultural e lingüística daqueles que tinham sido seus primeiros habitantes, os índios. É o que podemos acompanhar no texto "O moleque":

Reclus, na sua Georgrafia Universal tratando do Brasil, notava a necessidade de conservarmos os nomes tupis dos lugares de uma terra. (...) No Rio de Janeiro, há de fato nomes tupis tão eloqüentes, para traduzir a forma ou o encanto dos lugares que ficamos pasmos, quando lhes sabemos a significação, com o poder poético, com a força de emoção superior de que eram capazes os primitivos canibais habitantes desta região, diante dos aspectos da natureza tão bela e singular que é a que cerca e limita nossa cidade. Bastam os nomes da baia. Como não traduz bem a sua sedução, o seu recato, a sua fascinação, o nome: Guanabara - seio do mar? E se o mar abriu aqui um seio foi para nele esconder as suas águas - Niterói - água escondida. (...) os nomes indios (...) se apagam, vão se apagando, para dar lugar a nomes banais de figurões ainda mais banais, de forma que essa pequena antigüidade de quatro séculos desaparecerá em breve as novas denominações talvez não durem tanto.

Nenhum testemunho, dentro em pouco, haverá das almas que eles representam, dessas consciências tamoias que tentaram, com tais apelidos macular a virgindade da incalculável duração da terra. Sapopemba é já um general qualquer e tantos outros lugares do Rio de Janeiro vão perdendo insensivelmente os seus nomes tupis.

Inhaúma é ainda dos poucos lugares da cidade que conserva o seu primitivo nome caboclo, zombando dos esforços dos nossos edis para apagá-lo (Barreto, 1990: 17-19 grifos nossos).

Neste fragmento, as reflexões e ações de Lima Barreto e da sua personagem, Policarpo Quaresma, se projetam e se confundem. É inevitável que se traga à cena a imagem de Quaresma atracado "com o Montoya, Arte y dicionário de la lengua guarani ó 
más bien tupí, [estudando] o jargão caboclo com afinco e paixão". Como resultado do seu esforço, a personagem encontra no final a "incredulidade geral, o riso, a mofa, o escárnio, e a loucura" (Barreto, op. cit., p. 33). Fica claro no romance o embate entre o saber desinteressado de ambições mesquinhas e de poder, no caso de Policarpo, e o saber oficializado e detentor do poder instituído. A propósito, lembremos da ira do diretor da repartição de Quaresma, quando chega às suas mãos um requerimento redigido pelo Major, num momento de distração, em tupi-guarani:

- Quem escreveu isso? O major nem quis examinar o papel. Viu a letra, lembrou-se da distração e confessou com firmeza: - Fui eu. - Então confessa? - Pois não. Mas vossa Excelência não sabe... - Não sabe! Como é que o senhor ousa dizer-me isto? Tem o senhor porventura o curso de Benjamin Constant? Sabe o senhor Matemática, Astronomia, Física, Química, Sociologia e Moral? Como ousa então? Pois o senhor pensa que por ter lido uns romances e saber um francesinho aí, pode ombrear-se com quem tirou grau 9 em Cálculo, 10 em Mecânica, 8 em Astronomia, 10 em Hidráulica, 9 em Descritiva? Então! (...) Quaresma era doce, bom e modesto. Nunca fora seu propósito duvidar da sabedoria do seu diretor. Ele não tinha nenhuma pretensão a sábio e pronunciara a frase para começar a desculpa; mas quando viu aquela enxurrada de saber, de títulos, a sobrenadar em águas tão furiosas, perdeu o fio do pensamento, a fala, as idéias e nada mais soube nem pode dizer (p. 93-4).

Do olhar crítico e da pena carregada de Lima Barreto não escapam as várias esferas do poder, seja a do regime republicano que dele exclui quem a ele não se adequa $^{4}$, (como o próprio Policarpo Quaresma, sumariamente executado a mando de Floriano Peixoto); seja a dos "mandarins da literatura", expressão cunhada pelo escritor e que tem como referentes os grupos detentores da produção e da circulação de bens culturais, e que, segundo ele, se encastelavam nos grandes jornais cariocas, na Academia Brasileira de Letras e na livraria Garnier. Os ataques de Lima Barreto a tal "casa", tinham como motivo o monopólio que ela exercia no contexto editorial da época, além dos seus critérios para publicação. Segundo Lima Barreto, tais critérios eram: aproveitar pecuniariamente reputações feitas albures e os autores já comercialmente viáveis,

\footnotetext{
4 “A república do Brasil é o regímen da corrupção. Todas as opiniões devem, por esta ou aquela paga, ser estabelecidas pelos poderosos do dia. Ninguém admite que se divirja deles (...) proclamada que foi a república, ali, no Campo de Sant'Ana , por três batalhões, o Brasil perdeu a vergonha e seus filhos ficaram capachos (...). Não se admite mais independência de pensamento ou espírito. (...) Viva a República” (Barreto, "A política republicana”, Marginália, 1961: 79-80).
} 
para aumentar os lucros da casa, conforme explicita na crônica "O Garnier morreu" (1911). Nesta, o inconformado escritor vocifera contra aquele que até então dirigira a livraria/editora, H. Garnier, e que falecera recentemente em Paris:

um velho mentecapto, que nem lia português e nunca tinha vivido no nosso meio (...) o seu critério nas publicações era o dos pistolões recebidos e do nome que o autor tinha no mundo. (...) Foram-se os tempos do B. L. Garnier. Este viveu aqui, conhecia-nos, podia aquilatar o valor, não direi intelectual, mas, comercial de um livro; mas nesses últimos anos, sem ter ninguém propriamente dito, da casa que julgasse os manuscritos, sucediam-se borracheiras aparecidas chez Garnier (Barreto, 1993: 365-368).

Em outras duas crônicas, "Academia de Letras" e "Academia dos Moços", Lima Barreto ironiza ainda a obsessão dos "intelectuais" brasileiros de fundar academias. Em "Academia dos Moços", diz o cronista que não há dúvida alguma que o Brasil, além de essencialmente agrícola é evidentemente literário, arrematando em seguida:

Não há ano, não há dia, em que não se funde nestes brasis uma academia de letras. (...) Isto demonstra a nossa cultura e nega a tal história de analfabetismo que anda sendo por aí apregoada. Um país que tem tantas 'academias' não pode ser um país de analfabetos. Há de ser um país de gente culta que saiba ler e escrever, pelo menos por cima, porque não se pode admitir literatos que não tenham pelo menos esses dotes elementares (in Marginália, p. 134, grifos nossos).

Por todos esses Estados brasileiros, há academias literárias, todas elas com quarenta imortais, sendo os Estados vinte e incluindo a do Distrito Federal, vulgo, brasileira, temos, se a aritmética não falha, oitocentos e quarenta sumidades literárias, o que não é muito para país tão vasto e tão culto, como dizem ser o nosso ("Academia de Letras", in Vida urbana, 1961: 212; grifos nossos).

É sob a clave da exclusão, simultâneo a um desejo maior de um reconhecimento público/oficial do valor do seu trabalho de escritor, que Lima Barreto conduz seu embate com os "mandarins da literatura". Aqui podemos destacar o artigo no qual o criador de Policarpo Quaresma vem justificar, mais uma vez, sua candidatura à ABL:

Se não disponho do Correio da Manhã ou d'O Jornal, para me estamparem o nome e o retrato, sou alguma coisa nas letras brasileiras e ocultarem o meu nome ou o 
desmerecerem, é uma injustiça contra a qual eu me levanto com todas as armas ao meu alcance (Barreto: 1993: 383).

Pela terceira vez, Lima Barreto se candidatava a uma vaga na Academia Brasileira de Letras. Na primeira, em 1917, a inscrição não foi considerada; na segunda, na vaga aberta pela morte de Emílio de Menezes, quando foi eleito Humberto de Campos; e, em 1919, apresenta-se em agosto e no mês seguinte retira a candidatura.

A ambigüidade marca a relação de Lima Barreto com as instituições literárias, sobretudo com a Academia Brasileira de Letras. Ao mesmo tempo em que a vida desse escritor era marcada pela boemia, pela irreverência de forma e fundo, ele tinha consciência de que a profissionalização do escritor se tornava cada vez mais premente. Nesse sentido, a ABL fazia o papel de grande vitrine literária, expondo, tornando visíveis todos aqueles que, como Lima Barreto, queriam se inserir no mercado dos bens simbólicos.

Mesmo sendo um crítico mordaz da política cultural da ABL (tida por ele como instituição reguladora e corporativista), o autor de Feiras e mafuás não deixava de ter consciência do valor pragmático da instituição, quando nela reivindica um lugar: "Eu sou escritor e, seja grande ou pequeno, tenho direito a pleitear as recompensas que o Brasil dá aos que se distinguem na sua literatura” ("A minha candidatura”, Barreto, 1993: 383). É desse inconformado lugar de exclusão, tanto literária quanto social, que ele articula seus discursos, tendo como alvo os enganos e mazelas de uma viciada sociedade republicana.

Lima Barreto prima por denunciar os lances de fachada e as conspirações de bastidores de uma sociedade nostálgica do que não foi, ávida por etiquetas e jogos de salão europeus. Nos salões da belle époque brasileira, denuncia o escritor, prevalece quase sempre a frivolidade dos seus ocupantes, o grotesco de uma inteligência subalterna a valores importados, assimilados na epiderme, a alienação no que diz respeito aos problemas (políticos e sociais) e valores (multiculturais) do Brasil.

Em vez de estarmos aí a cantar cavalheiros de fidalguia suspeita e damas de uma aristocracia de armazém por atacado, porque moram em Botafogo ou Laranjeiras, devemos mostrar nas nossas obras que um negro, um indio, um português ou um italiano se podem entender e se podem amar, no interesse comum de todos (Barreto, "Literatura militante" [1918], Impressões de leitura, 1961: 73; grifos nossos).

\section{$\operatorname{soc} 2$}




\section{BIBLIOGRAFIA}

BARBOSA, Francisco Assis (1987). Lima Barreto e a reforma da sociedade. Recife: Pool.

BARBOSA, (1988). A vida de Lima Barreto. 7 ed., Belo Horizonte: Itatiaia.

BARRETO, Lima (1961). Coisas do Reino de Jambom. 2 ed., São: Brasiliense, v. VIII.

BARRETO, Lima (1961). Bagatelas. 2 ed., São Paulo: Brasilense, v. IX.

BARRETO, Lima (1961). Feiras e Mafuás. 2 ed,. São Paulo: Brasiliense, v. X.

BARRETO, Lima (1961). Vida urbana. 2 ed., São Paulo: Brasiliense, v.XI.

BARRETO, Lima (1961). Marginália. 2 ed., São Paulo: Brasiliense, v. XII.

BARRETO, Lima (1961). Impressões de leitura. 2 ed., São Paulo: Brasiliense.

BARRETO, Lima (1969). Triste fim de Policarpo Quaresma. 7 ed., São Paulo: Brasiliense.

BARRETO, Lima (1979). A nova Califórnia. São Paulo: Brasiliense.

BARRETO, Lima (1986). Os melhores contos; sel. de Francisco de Assis Barbosa, Rio de Janeiro: Global.

BARRETO, Lima (1990). Histórias e sonhos. Rio de Janeiro: Belo Horizonte: Garnier.

BARRETO, Lima (1993). Um longo sonbo do futuro: diários, cartas, entrevistas e confissões dispersas. Rio de Janeiro: Graphia Editorial.

BARRETO, Lima (s/d) Vida e morte de M. J. Gonzaga de Sá. Rio de Janeiro: Ed. Mérito.

BHABHA, Homi (1998). O local da cultura; trad. de Myriam Ávila, Eliana Lourenço de Lima Reis, Gláucia Renate Gonçalves. Belo Horizonte: Ed. UFMG.

BROCA, Brito (1975). A vida literária no Brasil-1900. 3 ed., Rio de Janeiro: José Olympio / Departamento de Cultura da Guanabara.

CANDIDO, Antonio (1995). Vários escritos. 3 ed. São Paulo, Duas Cidades.

CARVALHO, José Murilo de (et al. 1988). Sobre o Pré-Modernismo. Rio de Janeiro: Fundação Casa de Rui Barbosa.

FOUCAULT, Michel (1993). Microfísica do poder. 11 ed., trad. de Roberto Machado; Rio de Janeiro: Edições Graal.

HARDMAN, Francisco Foot (1988). Trem fantasma: a modernidade na selva. São Paulo: Companhia. das Letras.

SEVCENKO, Nicolau (1985). Literatura como missão: tensões sociais e criação cultural na Primeira República. São Paulo: Brasiliense.

Elvya Shirley Ribeiro Pereira é Professora Titular da Universidade Estadual de Feira de Santana. Graduada em Letras pela UEFS, Mestra em Literatura Brasileira pela UFPB, Doutora em Literaturas de Língua Portuguesa pela PUC/RJ. Publicou, recentemente, Piguara: Alencar e a invenção do Brasil (2000), na coleção "Literatura e Diversidade Cultural". 